\title{
Standardised material properties for numerical parametric studies of stainless steel structures and buckling curves for tubular columns
}

\author{
S. Afshan ${ }^{*(a)}$, O. Zhao ${ }^{(b)}$, L. Gardner ${ }^{(\mathrm{c})}$ \\ ${ }^{a}$ Brunel University London, United Kingdom \\ ${ }^{\mathrm{b}}$ Nanyang Technological University, Singapore \\ ${ }^{\mathrm{c}}$ Imperial College London, United Kingdom
}

\begin{abstract}
While the nominal material properties given in material specifications are suitable for design purposes, for the generation of realistic numerical parametric results that are 'equivalent' to physical experiments, material properties that are representative of actual structural members are required. Standardised values for these properties are proposed herein. Following analysis of a comprehensive database of material test data from different stainless steel products, values for the yield stress $f_{y}$, the ultimate tensile stress $\mathrm{f}_{\mathrm{u}}$, the strain at ultimate tensile stress $\varepsilon_{\mathrm{u}}$ and the Ramberg-Osgood parameters $\mathrm{n}$ and $\mathrm{m}$ are proposed. This enables the generation of standardised stress-strain curves for typical austenitic, duplex and ferritic stainless steel sections. Following this, an extensive numerical modelling study, incorporating the proposed standardised material parameters, was carried out to investigate the effect of production route (cold-formed and hot-finished) and material grade (austenitic, duplex and ferritic) on the flexural buckling behaviour and design of stainless steel square, rectangular and circular hollow section compression members. The FE generated flexural buckling data, combined with column test data from the literature, were used to derive a series of buckling curves for the design of stainless steel compression members. The suitability of the proposals was confirmed by means of reliability analysis.
\end{abstract}

Keywords: Buckling curves, Columns, Material modelling, Parametric study, Reliability, Stainless steel.

\section{Introduction}

Towards the development of more resilient and sustainable structures, interest in the use of high performance construction materials, such as stainless steels, has increased in recent years. Stainless steel has many desirable characteristics which can be exploited in a wide range of construction applications. It is corrosion-resistant and long lasting, making thinner and more durable structures possible. In recognition of the many desirable properties of stainless steel, a series of research projects to generate structural design rules have been carried out over the past few decades leading to the development of international design standards such as EN 1993-1-4 [1] in Europe, ASCE/SEI-8 [2] in the USA and AS/NZS 4673:2001 [3] in Australia and New Zealand. The guidelines provided in EN 1993-1-4 [1] are applicable to cold formed, hot-rolled and welded structural members, while those in ASCE/SEI-8 [2] and AS/NZS 4673:2001 [3] are for cold-formed members only. A new American stainless steel design guide, AISC Design Guide 27: Structural Stainless Steel [4], covering hot-rolled and welded stainless steel structural sections was published in 2013 by the American Institute of Steel Construction (AISC). The fourth edition of the Design Manual for Structural Stainless Steel [5] produced by the Steel Construction Institute was also recently published.

The stress-strain behaviour of stainless steel is different from that of carbon steels in that instead of the typical linear elastic behaviour up to the yield stress and a plateau before strain hardening, it exhibits a more rounded response, with no sharply-defined yield stress. In the absence of a distinct yield point, an equivalent yield stress is generally defined in terms of a proof stress at a particular offset strain, conventionally the $0.2 \%$ strain. The Ramberg-Osgood formulation in the forms proposed by Mirambell and Real [6], Rasmussen [7] and Gardner and Ashraf [8] has been commonly used to describe the nonlinear stress-strain response of stainless steels in numerical modelling studies of stainless steel 
structural components. The stress-strain characteristics of stainless steels depend on the chemical composition of the material and therefore vary between the different grades. Fig. 1 shows typical measured stress-strain curves for austenitic, duplex and ferritic stainless steel grades [9]. The material characteristics are also influenced by the production process and, in particular the level of cold-work experienced. The degree of nonlinearity of the stress-strain behaviour affects the buckling strength of columns, though this is currently not reflected in EN 1993-1-4 [1] for tubular sections, since a single buckling curve is used for all stainless steel grades and section forming routes, which was shown in [10] to lead to inaccurate resistance predictions.

This paper begins with an analysis of an extensive database of stainless steel material test results, collected in $[10,11]$, to derive 'standardised' representative values for key material parameters: the yield stress $\mathrm{f}_{\mathrm{y}}$, taken as the $0.2 \%$ proof stress, the ultimate tensile stress $\mathrm{f}_{\mathrm{u}}$, the strain at ultimate tensile stress $\varepsilon_{\mathrm{u}}$ and the Ramberg-Osgood model parameters $\mathrm{n}$ and $\mathrm{m}$ for use in numerical parametric investigations of stainless steel structures. The test database comprised experimental stress-strain curves from a range of stainless steel alloys, grouped by grade - austenitic, duplex and ferritic grades, and by product type: (1) hot-rolled sections, hot-rolled plates and sheets and cold-formed sheets, (2) flat faces of cold-formed box-sections and curved walls of cold-formed CHS and (3) corner regions of cold-formed box-sections and corner regions of press-braked sections. A finite element (FE) modelling study is then described. The FE models were used to generate structural performance data to derive buckling curves for the design of stainless steel square, rectangular and circular hollow sections (SHS, RHS and CHS respectively) compression members from two production routes - cold-forming and hot-finishing, and three material grades - austenitic, duplex and ferritic. The numerical models were first validated against suitable test results from the literature, and parametric studies were subsequently performed to generate further data over a wider range of member non-dimensional slendernesses for each of the cross-section types, material grades, and production processes considered. The material properties used in the parametric study were based on the standardised representative values recommended in Section 2.

\section{Standardised material parameters for numerical parametric studies}

An accurate description of the material stress-strain response is a crucial aspect of numerical modelling of structural elements. While the nominal material properties given in material specifications are suitable for design purposes (either for use in member checks or in design by advanced computational analysis), for the generation of realistic numerical parametric results that are 'equivalent' to physical experiments, material properties that are representative of actual structural members are required. Such properties are recommended in this section of the paper.

The Ramberg-Osgood material model originally proposed to describe the nonlinear stress-strain response of aluminium alloys has been extended to stainless steel materials over the past two decades, and is commonly employed in numerical modelling studies of stainless steel structures in a two-stage form[6,7,12]. The two-stage model, given by Eqs. (1) and (2), is capable of accurately capturing the nonlinear stress-strain response of the material over the full strain range.

$$
\begin{gathered}
\varepsilon=\frac{\mathrm{f}}{\mathrm{E}}+0.002\left(\frac{\mathrm{f}}{\mathrm{f}_{\mathrm{y}}}\right)^{\mathrm{n}} \quad \text { for } \mathrm{f} \leq \mathrm{f}_{\mathrm{y}} \\
\varepsilon=\frac{\mathrm{f}-\mathrm{f}_{\mathrm{y}}}{\mathrm{E}_{0.2}}+\left(\varepsilon_{\mathrm{u}}-\varepsilon_{\mathrm{t}, 0.2}-\frac{\mathrm{f}_{\mathrm{u}}-\mathrm{f}_{\mathrm{y}}}{\mathrm{E}_{0.2}}\right)\left(\frac{\mathrm{f}-\mathrm{f}_{\mathrm{y}}}{\mathrm{f}_{\mathrm{u}}-\mathrm{f}_{\mathrm{y}}}\right)^{\mathrm{m}}+\varepsilon_{\mathrm{t}, 0.2} \text { for } \mathrm{f}_{\mathrm{y}}<\mathrm{f} \leq \mathrm{f}_{\mathrm{u}}
\end{gathered}
$$

where, $\varepsilon$ and $f$ are the engineering strain and stress respectively, $E$ is the Young's modulus, $f_{y}$ is the yield stress taken as the $0.2 \%$ proof stress, $\mathrm{f}_{\mathrm{u}}$ is the ultimate tensile stress, $\mathrm{E}_{0.2}$ is the tangent modulus at the $0.2 \%$ proof stress, $\varepsilon_{\mathrm{t}, 0.2}$ is the total strain at the $0.2 \%$ proof stress, $\varepsilon_{\mathrm{u}}$ is the strain at the ultimate tensile stress and $\mathrm{n}$ and $\mathrm{m}$ are the model parameters. 
For the validation of numerical models against experimental results, the measured stress-strain curves would typically be employed. The measured stress-strain data could either be input directly into the numerical simulation, or first used to fit the two-stage Ramberg-Osgood formulation, from which data can be extracted and input. The latter approach is sometimes useful to remove fluctuations in measured stress-strain curves arising from 'noise' in the recorded data, and, by providing the key RambergOsgood parameters, the curves can be replicated by others. For design through computational analysis, the nominal material properties provided in design standards will generally be the most appropriate. However, for numerical parametric studies as widely used by researchers to generate additional structural performance data that are equivalent to experiments, material properties that are representative of real cross-sections are needed. To this end, typical values for the key stress-strain parameters (yield stress $f_{y}$ taken as the $0.2 \%$ proof stress, ultimate tensile stress $f_{u}$, strain at ultimate tensile stress $\varepsilon_{\mathrm{u}}$ and Ramberg-Osgood model parameters $\mathrm{n}$ and $\mathrm{m}$ ) from a database of material tests collected in $[10,11]$ were sought.

The database comprised experimental stress-strain curves from a range of stainless steel alloys, grouped into austenitic, duplex and ferritic grades. The results were also grouped by types of product that exhibit similar characteristics. The following groups were identified: (1) hot-rolled sections, hot-rolled plates and sheets and cold-formed sheets, (2) flat faces of cold-formed box-sections and curved walls of coldformed CHS and (3) corner regions of cold-formed box-sections and corner regions of press-braked sections. Average values from the experimental database for the key material parameters in each of these groups and the structural sections that they may be applied to are listed in Table 1, and referred to as 'basic material properties'. The recommended $f_{y}$ and $f_{u}$ values for the hot-rolled sections, hot-rolled plates and sheets and cold-formed sheets tie in with the $0.2 \%$ proof stress and the ultimate tensile stress over-strength factors (i.e. mean-to- nominal strength ratios) $\mathrm{f}_{\mathrm{y} \text {,mean }} / \mathrm{f}_{\mathrm{y}, \text { nom }}=1.3$ for austenitic, 1.2 for ferritic and 1.1 for duplex stainless steels and $\mathrm{f}_{\mathrm{u}, \mathrm{mean}} / \mathrm{f}_{\mathrm{u}, \mathrm{nom}}=1.1$ for all stainless steel grades, respectively, proposed in [10]. The coefficient of variations (COVs) associated with the recommended average yield stress fy were as follows: for (1) hot-rolled sections, hot-rolled plates and sheets and cold-formed sheets: $0.11,0.13$ and 0.13 for the austenitic, duplex and ferritic grades, respectively, for (2) flat faces of coldformed box-sections and curved walls of cold-formed CHS: $0.29,0.21$ and 0.14 for the austenitic, duplex and ferritic grades, respectively and for (3) corner regions of cold-formed box-sections and corner regions of press-braked sections: $0.15,0.06$ and 0.10 for the austenitic, duplex and ferritic grades, respectively. The generally higher variation of $f_{y}$ exhibited by the cold-formed material is expected owing to the dependency on the section geometry.

The above 'basic material properties' correspond to average measured values across a range of products and sections. However, for sections that experience cold-work during the forming process, the material properties will in fact be cross-section specific since the level of cold-work, which influences the resulting stress-strain curve, is dependent on the section geometry. To reflect this, and as an alternative to the basic material properties, section specific material properties may be determined for press-braked sections and cold-formed tubular sections using predictive models developed in previous studies $[11,13]$. Note that, due to the dependency on section geometry, the section specific material properties will sometimes be above the basic (average) values and sometimes below.

For the section specific material yield stress $f_{y, c f}$, Eq. (3) may be employed for the corner regions of press-braked sections and cold-formed box sections, Eq. (4) for the flat faces of cold-formed box sections and Eq. (5) for the curved walls of CHS. These equations were derived in [13], but note that the 0.85 factor, which was included in [13] primarily for the purposes of achieving a required level of reliability in design calculations, has been omitted herein, since representative values of equivalent test specimens are sought.

$$
\mathrm{f}_{\mathrm{y}, \mathrm{cf}}=\mathrm{K}\left(\varepsilon_{\mathrm{c}}+\varepsilon_{\mathrm{t}, 0.2}\right)^{\mathrm{n}_{\mathrm{p}}} \quad \text { and } \quad \mathrm{f}_{\mathrm{y}} \leq \mathrm{f}_{\mathrm{y}, \mathrm{cf}}<\mathrm{f}_{\mathrm{u}}
$$




$$
\begin{gathered}
\mathrm{f}_{\mathrm{y}, \mathrm{cf}}=\mathrm{K}\left(\varepsilon_{\mathrm{f}}+\varepsilon_{\mathrm{t}, 0.2}\right)^{\mathrm{n}_{\mathrm{p}}} \quad \text { and } \quad \mathrm{f}_{\mathrm{y}} \leq \mathrm{f}_{\mathrm{y}, \mathrm{cf}}<\mathrm{f}_{\mathrm{u}} \\
\mathrm{f}_{\mathrm{y}, \mathrm{cf}}=\mathrm{K}\left(\varepsilon_{\mathrm{cHS}}+\varepsilon_{\mathrm{t}, 0.2}\right)^{\mathrm{n}_{\mathrm{p}}} \quad \text { and } \quad \mathrm{f}_{\mathrm{y}} \leq \mathrm{f}_{\mathrm{y}, \mathrm{cf}}<\mathrm{f}_{\mathrm{u}}
\end{gathered}
$$

The parameters $\mathrm{K}$ and $\mathrm{n}_{\mathrm{p}}$ are defined by Eqs. (6) and (7) and relate to the material properties of the flat sheet prior to section forming $\left(\mathrm{f}_{\mathrm{y}}, \mathrm{f}_{\mathrm{u}}\right.$ and $\varepsilon_{\mathrm{u}}$, with $\left.\varepsilon_{\mathrm{t}, 0.2}=\mathrm{f}_{\mathrm{y}} / \mathrm{E}+0.002\right)$, which may be taken as the basic material properties from the first three rows of Table 1.

$$
\begin{gathered}
\mathrm{K}=\frac{\mathrm{f}_{\mathrm{y}}}{\varepsilon_{\mathrm{t}, 0.2}} \\
\mathrm{n}_{\mathrm{p}}=\frac{\ln \left(\mathrm{f}_{\mathrm{y}} / \mathrm{f}_{\mathrm{u}}\right)}{\ln \left(\varepsilon_{\mathrm{t}, 0.2} / \varepsilon_{\mathrm{u}}\right)}
\end{gathered}
$$

The three strain parameters $\varepsilon_{\mathrm{c}}, \varepsilon_{\mathrm{f}}$ and $\varepsilon_{\mathrm{CHS}}$ refer to the strain induced during the forming of the corner regions of press-braked sections and cold-formed box sections, the flat regions of cold-formed box sections and the curved walls of cold-formed CHS; these are defined by Eqs. (8), (9) and (10), respectively.

$$
\begin{gathered}
\varepsilon_{\mathrm{c}}=\frac{\mathrm{t}}{2\left(2 \mathrm{r}_{\mathrm{i}}+\mathrm{t}\right)} \\
\varepsilon_{\mathrm{f}}=\left[\frac{\mathrm{t}}{900}\right]+\left[\frac{\pi \mathrm{t}}{2(\mathrm{~b}+\mathrm{h}-2 \mathrm{t})}\right] \\
\varepsilon_{\mathrm{CHS}}=\frac{\mathrm{t}}{2(\mathrm{~d}-\mathrm{t})}
\end{gathered}
$$

in which $b, h, d, t$ and ri are the section breadth, height, diameter, thickness and internal corner radius, respectively.

For the section specific material ultimate stress $f_{u, c f}$, Eq. (11) and Eq. (12), derived in [11,14], may be used for austenitic/duplex and ferritic stainless steels, respectively.

$$
\begin{gathered}
f_{u, c f}=\frac{f_{y, c f}}{\left[0.2+185 f_{y, c f} / E\right]} \quad \text { for austenitic and duplex stainless steels } \\
f_{u, c f}=\frac{f_{y, c f}}{\left[0.46+145 f_{y, c f} / E\right]} \quad \text { for ferritic stainless steels }
\end{gathered}
$$

For the section specific material ultimate strain eu,cf, Eq. (13) derived in [13] and Eq. (14), derived in [14] may be used for austenitic/duplex and ferritic stainless steels, respectively.

$$
\begin{gathered}
\varepsilon_{\mathrm{u}, \mathrm{cf}}=1-\frac{\mathrm{f}_{\mathrm{y}, \mathrm{cf}}}{\mathrm{f}_{\mathrm{u}, \mathrm{cf}}} \quad \text { for austenitic and duplex stainless steels } \\
\varepsilon_{\mathrm{u}, \mathrm{cf}}=0.6\left[1-\frac{\mathrm{f}_{\mathrm{y}, \mathrm{cf}}}{\mathrm{f}_{\mathrm{u}, \mathrm{cf}}}\right] \quad \text { for ferritic stainless steels }
\end{gathered}
$$

For the section specific stress-strain curves, the average values of $n$ and $m$ given in the bottom three rows of Table 1 under basic material properties are proposed. Also provided in Table 1 are 
recommendations for residual stresses and initial geometric imperfections for the modelling of structural stainless steel sections.

Within each of the stainless steel grades, the values follow the expected trend of increasing strength, in terms of both fy and $f_{u}$, and reduction in ductility $\varepsilon_{u}$ with increased level of cold-work from hot-rolled sections, hot-rolled plates and sheets and cold-formed sheets to the flat faces of cold-formed tubular sections and to the corner regions of cold-formed tubular and press-braked sections. The increase in strength of the flat faces of cold-formed tubular sections over the hot-rolled sections, hot-rolled plates and sheets and cold-formed sheets is associated with the cold-work induced during the section forming of these products [13]. This increase in strength is even more pronounced for the corner regions of coldformed sections which undergo higher levels of cold-worked induced plastic strains during the section forming process. The increased degree of nonlinearity of the stress-strain curve in the initial stage of the curve, up to the $0.2 \%$ proof stress, with increasing level of cold-work is also apparent from the recommended Ramberg-Osgood $\mathrm{n}$ values. Similarly, for specific material properties, geometries that require higher levels of cold-work (i.e. thicker sections and tighter bend radii) result in higher strengths and lower ductilities as observed in practice.

The 'basic material properties' presented in Table 1 in this section are employed in the numerical study described in Section 4, where the buckling response of hot-finished and cold-formed stainless steel tubular columns is investigated. It is also recommended that these properties are employed by others performing parametric studies aiming to derive results that are equivalent to those obtained through experimentation.

\section{Current design methods for stainless steel compression members}

\subsection{EN 1993-1-4 method}

The EN 1993-1-4 [1] design approach for the flexural buckling of compression members is based on the Perry-Robertson formulation. It is derived on the basis of a first-yield criterion of a concentrically loaded elastic column with a sinusoidal geometric imperfection. A linear imperfection parameter $\eta=\alpha\left(\bar{\lambda}-\bar{\lambda}_{0}\right)$ is employed, where $\alpha$ and $\bar{\lambda}_{0}$ are constants which account for the effects of geometric imperfections and residual stresses on the column strength. The effect of gradual material yielding is not explicitly accounted for in the member buckling formulations. The non-dimensional buckling reduction factor $\chi$ is given by Eq. (15), where $\varphi$ is defined in Eq. (16) and $\bar{\lambda}$ is the non-dimensional member slenderness, taken as the square root of the ratio of the yield load $\mathrm{N}_{\mathrm{y}}$ to the elastic buckling load $\mathrm{N}_{\mathrm{cr}}$. Three sets of buckling curves, each with different values for the imperfection factor $\alpha$ and the non-dimensional limiting slenderness (i.e. the plateau length) $\bar{\lambda}_{0}$, are set out in EN 1993-1-4 [1] and applied to different columns, depending on the cross-section shape, production route and axis of buckling. For cold-formed open sections and cold-formed and hot-finished hollow sections, $\alpha$ and $\bar{\lambda}_{0}$ values of 0.49 and 0.40 , respectively are adopted. For welded open sections, $\alpha=0.49$ with $\bar{\lambda}_{0}=0.2$ and $\alpha=0.76$ with $\bar{\lambda}_{0}=0.2$ are given for major axis and minor axis buckling, respectively. These buckling curves were developed based on the stainless steel test data available during the preparation of EN 1993-1-4, and were calibrated against the test data to provide a suitably conservative fit for design purposes; these buckling curves are common to all stainless steel grades. The flexural buckling resistance of a stainless steel compression member $\mathrm{N}_{\mathrm{b}, \mathrm{Rd}}$, is obtained from Eq. (17), where $\mathrm{f}_{\mathrm{y}}$ is the material yield strength (taken as the $0.2 \%$ proof strength), $\mathrm{A}$ is the cross-sectional area (taken as the gross cross-sectional area for Class 1, 2 and 3 sections and an effective cross-sectional area $A_{\text {eff }}$ for Class 4 sections), $\gamma_{\mathrm{M} 1}$ is the partial resistance factor for member resistance (taken as 1.1 in EN 1993-14 [1]) and $\chi$ is the flexural buckling reduction factor, obtained from the appropriate buckling curve. 


$$
\begin{gathered}
\chi=\frac{1}{\varphi+\sqrt{\varphi^{2}-\bar{\lambda}^{2}}} \text { but } \chi \leq 1.0 \\
\varphi=0.5\left[1+\eta+\bar{\lambda}^{2}\right] \\
\mathrm{N}_{\mathrm{b}, \mathrm{Rd}}=\frac{\chi \mathrm{Af}_{\mathrm{y}}}{\gamma_{\mathrm{M} 1}}
\end{gathered}
$$

\subsection{ASCE/SEI-8 method}

The SEI/ASCE-8 [2] provisions for stainless steel column design are based on the tangent modulus theory of buckling to allow for the nonlinear stress-strain response of the material. The tangent modulus $\mathrm{E}_{\mathrm{t}}$, corresponding to the buckling stress, instead of the initial modulus $\mathrm{E}$ is used to determine the member buckling resistance. While this approach can give more accurate predictions of member buckling resistance, it requires iteration. The flexural buckling stress $f_{n}$ is determined from Eq. (18), where $E_{t}$ is the tangent modulus corresponding to the buckling stress, $\mathrm{K}$ is the effective length factor, $\mathrm{L}$ is member length, $r$ is the radius of gyration and $\mathrm{f}_{\mathrm{y}}$ is the yield stress. The tangent modulus $\mathrm{E}_{\mathrm{t}}$ at the buckling stress $\mathrm{f}$ is determined from the Ramberg- Osgood relationship as given by Eq. (19), where $\mathrm{n}$ is the model parameter representing the degree of nonlinearity of the stress-strain curve up to the $0.2 \%$ proof stress point.

$$
\begin{gathered}
f_{n}=\frac{\pi^{2} E_{t}}{(K L / r)^{2}} \leq f_{y} \\
E_{t}=\frac{f_{y} E}{f_{y}+0.002 n E\left(f / f_{y}\right)^{n}}
\end{gathered}
$$

\subsection{AS/NZS 4673:2001 method}

In the AS/NZS 4673 [3] standard, two methods for determining the buckling resistance of cold-formed stainless steel compression members are specified: (1) an iterative method based on the tangent modulus approach, as used in the SEI/ASCE-8 Specification [2] and (2) an explicit design procedure based on the Perry-Robertson formulation, similar to that provided in EN1993-1-4 [1]. The explicit design approach uses a nonlinear expression for the imperfection parameter $\eta$, as defined by Eq. (20), but is otherwise the same as to the Perry-Robertson equation used in EN 1993-1-4. This choice of imperfection parameter was based on the investigation carried out by Rasmussen and Rondal [15], where finite element analyses were carried out on stainless steel columns of varying slenderness $\bar{\lambda}$ and with a wide range of mechanical properties, represented by the Ramberg-Osgood parameters $E, f_{0.2}$ and $n$. It was shown that while a linear imperfection parameter $\eta$ is appropriate for material with a high $n$ value, such as structural carbon steel, it does not provide accurate predictions for nonlinear materials with lower $n$ values, such as stainless steel. In Eq. (20), the parameters $\alpha, \bar{\lambda}_{1}, \beta$ and $\bar{\lambda}_{0}$ are used to represent the influence of the varying degrees of nonlinearity displayed by the different stainless steel grades on the predicted compressive buckling resistance. Expressions for $\alpha, \bar{\lambda}_{1}, \beta$ and $\bar{\lambda}_{0}$ in terms of the Ramberg-Osgood parameters $\mathrm{n}, \mathrm{f}_{0.2}$ and $\mathrm{E}$ were developed in [14], from which the values in Table 3.4.2 in Clause 3.4.2 of AS/NZS 4673 [3]were derived. A total of five buckling curves are provided for different stainless steel grades: austenitic (EN 1.4301, 1.4401, 1.4306 and 1.4404), ferritic (EN 1.4512, 1.4003 and 1.4016), and duplex (EN 1.4462).

$$
\eta=\alpha\left[\left(\bar{\lambda}-\bar{\lambda}_{1}\right)^{\beta}-\bar{\lambda}_{0}\right]
$$




\section{Numerical modelling}

In this section, a parametric numerical study, utilising the material properties derived in Section 2, is presented to examine the behaviour of stainless steel tubular columns of different grades and produced via different fabrication routes. The nonlinear finite element analysis package ABAQUS [16] was used for conducting the numerical analyses. Numerical simulations were carried out on stainless steel SHS, RHS and CHS columns of varying member slenderness subjected to axial compression. A description of the development of the FE models and their validation against experimental results were presented by the authors in previous numerical studies $[17,18]$ of stainless steel tubular sections; hence only the key features of the modelling are reported herein.

\subsection{General modelling assumptions}

Shell elements were adopted to simulate the stainless steel tubular hollow section columns, as is customary for modelling of thin-walled structures. The four-noded doubly curved shell element with reduced integration and finite membrane strain S4R, which has performed well in numerous similar applications [19-21], was used. An element size equal to the cross-section thickness was used to discretise the flat portions of the modelled SHS/RHS cross-sections, while the corner regions were assigned a finer mesh of four elements to accurately represent the curved geometry. An element size equal to the cross-section thickness was also employed for the CHS models. The end section boundary conditions of the numerical models were arranged to replicate pin-ended conditions about the specified axis of buckling. Symmetry was exploited by modelling only half the cross-section and member length of the concentrically- loaded compressive members and then by applying suitable symmetry boundary conditions to each axis of symmetry.

\subsection{Material modelling}

The adopted material properties for the present numerical modelling were taken as the 'basic material properties' recommended in Table 1. Stress-strain curves were constructed using the two-stage Ramberg-Osgood material model given by Eqs. (1) and (2) based on the material parameters in Table 1. The Young's modulus was taken as $200,000 \mathrm{~N} / \mathrm{mm}^{2}$ for all stainless steel grades $[10,11]$. For the flat faces of the cold-formed SHS and RHS, stress-strain curves were constructed from the recommended flat material properties and assigned to the flat faces of the sections. For the corner regions of the coldformed SHS and RHS, stress-strain curves were constructed from the recommended corner material properties and assigned to the curved corner regions plus an extension of $2 \mathrm{t}$, where $\mathrm{t}$ is the material thickness, in accordance with findings in [23], which showed that both of the aforementioned regions undergo approximately the same degree of strength enhancement during the cold-rolling process, and therefore exhibit similar stress-strain responses. The recommended material properties for the hot-rolled section, plate and sheet material were used for simulating the response of the hot-finished SHS, RHS and CHS members. Cold-formed stainless steel CHS columns have been studied elsewhere [22]. ABAQUS [16] requires the material properties to be specified in the form of true stress and log plastic strain for the adopted element type; these were derived from the engineering stress-strain curves by means of Eqs. (21) and (22). Owing to the negligible influence of the membrane residual stresses on cold-formed stainless steel tubular profiles, and the inherent presence of through-thickness residual stresses in the measured material properties [18], residual stresses were not explicitly modelled in the FE models of the cold-formed sections. Also, since the magnitude of measured residual stresses in hotfinished tubular sections are very low [24], as reflected by the use of buckling curve a in EN 1993-1-1 [25], residual stresses were not included in the FE models of the hot-finished sections.

$$
\begin{gathered}
\sigma_{\text {true }}=\sigma_{\text {nom }}\left(1+\varepsilon_{\text {nom }}\right) \\
\varepsilon_{\text {true }}=\ln \left(1+\varepsilon_{\text {nom }}\right)-\frac{\sigma_{\text {true }}}{E}
\end{gathered}
$$




\subsection{Geometric imperfections and boundary conditions}

All the modelled columns had pin-ended boundary conditions, where the loaded end section was coupled to a concentric reference point allowing longitudinal translation and rotation about the axis of buckling; the axial load was applied to the model through this reference point - see Fig. 2. Initial geometric imperfections are introduced into structural sections during production, fabrication and handling and can significantly influence structural behaviour; initial imperfections were therefore incorporated into the numerical models. The imperfection shapes were taken in the form of the lowest global and local buckling modes obtained from a prior linear elastic eigenvalue buckling analysis. The global imperfection amplitude was set to $\mathrm{L} / 1000$, where $\mathrm{L}$ is the overall column length. For the SHS and RHS members, the local imperfection amplitudes $\omega 0$ were determined by means of the Dawson and Walker model, as adapted for stainless steel [26], as given by Eq. (23), where $t$ is the thickness, $f_{y}$ is the material yield strength and $\mathrm{f}_{\mathrm{cr} \text {, min }}$ is the minimum elastic buckling stress of all the plate elements making up the cross-section. The local imperfection amplitude of the CHS members was set to $t / 100$; this was found in [27] to give good agreement between the test and FE results for stainless steel CHS stub columns under combined axial load and bending.

$$
\omega_{0}=0.023\left(\mathrm{f}_{\mathrm{y}} / \mathrm{f}_{\mathrm{cr}, \text { min }}\right) \mathrm{t}
$$

\subsection{Parametric studies}

For both the cold-formed and hot-finished SHS/RHS and the hot-finished CHS members, parametric studies were conducted where the varied parameters were: the stainless steel grade (austenitic, duplex and ferritic), the cross-section aspect ratio $(\mathrm{h} / \mathrm{b})$, the cross-section slenderness $(\mathrm{c} / \mathrm{t} \varepsilon)$, the axis of buckling and the member slenderness $(\bar{\lambda})$. The geometric dimensions of the modelled cross-sections of the SHS/RHS members were fixed to $100 \times 100,150 \times 100$ and $200 \times 100 \mathrm{~mm}$, giving cross-section aspect ratios $(\mathrm{h} / \mathrm{b})$ of $1,1.5$ and 2 . For each section, two thicknesses were considered corresponding to $(\mathrm{c} / \mathrm{t} \varepsilon)$ ratios for a Class 1 and a Class 3 cross-section according to the EN 1993-1-4 [1] classification limits. For the $150 \times 100$ and $200 \times 100$ cross-sections, buckling about both the major and minor axes was considered to investigate if different buckling curves should be provided for each buckling axis. Similarly, for the CHS members, the outer diameter was fixed to $100 \mathrm{~mm}$ and three thicknesses were considered corresponding to $\left(\mathrm{D} / \mathrm{t} \varepsilon^{2}\right)$ ratios for a Class 1, Class 2 and Class 3 cross-section according to the EN 1993-1-4 [1] classification limits. For each of the SHS/RHS and CHS models, the member lengths were varied, leading to a spectrum of member slenderness values $\bar{\lambda}$ from 0.1 to 2.5 . The internal corner radii of the SHS/RHS were set equal to the cross-section thickness t.

\section{Analysis of results and design guidance}

A comparison of the parametric results obtained in Section 4 with the current column buckling curves adopted in the European and Australian/ New Zealand standards is presented in this section. For the case of cold-formed SHS/RHS columns, test data on stainless steel compression members collected from the literature [12,28-43] are also included in the comparisons. Experimental results are not available for the other considered member types. Fig. 3 shows the FE and test ultimate loads normalised by the cross-section yield loads, defined as the product of the cross-sectional area A and the crosssection yield strength $\mathrm{f}_{\mathrm{y}}$, plotted against the member slenderness $\bar{\lambda}$ for the cold-formed austenitic, duplex and ferritic SHS/RHS members. Fig. 4 shows similar results for the hot-finished austenitic, duplex and ferritic SHS/RHS members. For the cold-formed sections, the cross-section yield strength $\mathrm{f}_{\mathrm{y}}$ is taken as the weighted average (by area) $0.2 \%$ proof stress i.e. normalising out the strength enhancements in the corner regions of the cold-formed sections. The EN 1993-1-4 [1] buckling curve for both cold-formed and hot-finished hollow sections, with the imperfection factor $\alpha=0.49$ and $\bar{\lambda}_{0}=0.4$, as well as the AS/NZS 4673 [3] buckling curve, which is applicable to cold-formed sections only, for each of the stainless steel grades, are also depicted in Figs. 3 and 4. 
The results for the hot-finished CHS columns are plotted in Fig. 5, where the EN 1993-1-4 [1] design buckling curve is also depicted. The EN 1993-1-4 [1] buckling curve, with $\alpha=0.49$ and $\bar{\lambda}_{0}=0.4$, was shown in [10] to give a number of predictions for cold-formed CHS members on the unsafe side, and, the need for a lower buckling curve or a partial safety factor greater than the current value of $\gamma_{\mathrm{M} 1}=1.10$ was emphasised. Similar observations were made in previous studies [15,44-46]. A new lower buckling curve with a plateau of $\bar{\lambda}_{0}=0.2$ and an imperfection factor of $\alpha=0.49$ was proposed in [22] for all stainless steel grades; this was based on a comprehensive analysis of available test and FE data. The required partial safety factors with the new proposed curve were found, following a reliability analysis conducted in accordance with Annex D of EN 1990 [47], to be: $\gamma_{\mathrm{M} 1}=1.14, \gamma_{\mathrm{M} 1}=1.06$ and $\gamma_{\mathrm{M} 1}=1.13$, for austenitic, duplex and ferritic stainless steel grades, respectively [22]. This buckling curve for coldformed CHS compression members is also shown in Fig. 5 for comparison purposes. To allow suitable comparison with the test and FE data, the measured geometries and material properties from the tests/FE models are adopted in all calculations and all partial safety factors have been set to unity.

At high slenderness, column failure is dominated by elastic buckling, and the average stress at failure lies within the linear portion of the stress-strain curve. Hence, in this region, as expected, there is little or no difference in the buckling strength of columns of different stainless steel grades, assuming similar levels of geometric imperfections and residual stresses. This is clearly evident from Figs. 3 and 4 for SHS/RHS and Fig. 5 for CHS members, where the FE and test data are well represented by the codified curves in this slenderness range. At low slenderness, i.e. in the plateau region, columns attain or exceed the squash load $\mathrm{Af}_{\mathrm{y}}$, where the influence of different strain hardening rates, which are highest for austenitic and lowest for ferritic stainless steels, may be observed, as shown in Figs. 3, 4 and 5. The limiting slenderness, beyond which member buckling rather than cross-section yielding becomes important, i.e. the length of the plateau region, depends on a combination of the following parameters: the $\mathrm{n}$ factor of the Ramberg-Osgood representation of the stress-strain behaviour, the yield stress $\mathrm{f}_{\mathrm{y}}$ and the Young's modulus E. In the intermediate slenderness range, where the average buckling stress falls between the limit of proportionality and the $0.2 \%$ proof stress, the nonlinear stress-strain response of stainless steel leads to different buckling responses between the different stainless steel grades. The current EN 1993-1-4 buckling curve is clearly not suitable for all stainless steel grades with varying nonlinear response characteristics.

For the cold-formed SHS/RHS members, revised buckling curves with an imperfection factor $\alpha=0.49$ for all grades and a plateau length $\bar{\lambda}_{0}=0.3$ for the austenitic and duplex grades and $\bar{\lambda}_{0}=0.2$ for the ferritic grades are proposed herein, and are plotted in Fig. 3. The buckling curves provided in AS/NZS 4673 [3] for cold-formed members are also depicted in Fig. 3, which for the austenitic and ferritic grades lie considerably below the test and FE data and for duplex grade is close to the curve proposed herein but with a slightly longer plateau.

Buckling curves of the same form as the EN 1993-1-4 formulation were also fitted to the normalised FE data for the hot-finished tubular stainless steel columns, and are shown in Fig. 4. The proposed curves have a plateau length $\bar{\lambda}_{0}=0.2$ for all grades and an imperfection factor $\alpha=0.49$ for the austenitic and duplex grades and $\alpha=0.34$ for the ferritic grades. Note that the positioning of the buckling curves needs to be considered in conjunction with the reliability analysis; the hot-finished duplex data, for example, appears further above the proposed buckling curve than the other grades, but this material also exhibits the lowest over-strength factor [10], and the resulting required $\gamma_{\mathrm{M} 1}$ factors are in fact rather consistent across the grades, as shown in Section 6.

For the hot-finished CHS members, revised buckling curves with $\alpha=0.49$ and $\bar{\lambda}_{0}=0.2$ for the austenitic and duplex grades and $\alpha=0.34$ and $\bar{\lambda}_{0}=0.2$ for the ferritic grades are proposed herein - see Fig. 5 . Table 2 presents a summary of the proposed imperfection factor $\alpha$ and plateau length $\bar{\lambda}_{0}$ values for coldformed SHS/RHS and hot-finished SHS/RHS and CHS in the austenitic, duplex and ferritic stainless steel grades. 


\section{Reliability analysis}

Statistical analyses in accordance with Annex D of EN1990 [47] were performed to assess the reliability of the proposed buckling curves for the cold-formed and hot-finished austenitic, duplex and ferritic SHS/RHS and CHS stainless steel columns. The numerical results from the parametric studies performed in Section 4 and the collected test data are used in the statistical analyses. Representative mean to nominal yield strength ratios $f_{y, \text { mean }} / f_{y, n o m}$ (i.e. material over-strength factors) and coefficients of variation (COV) of yield strength equal to 1.3 and 0.060 for austenitic, 1.1 and 0.030 for duplex and 1.2 and 0.045 for ferritic stainless steels, as recommended in [10] were employed. For the variability of the geometric properties, a COV value of 0.05 was used [10]. In order to add artificial variability to the numerical results, an additional variability term with coefficient of variation VFEM set to 0.03, which was determined by considering the deviation between the experimental and numerical results, as used in similar studies in [48], was also incorporated in the reliability analysis. For the purpose of the reliability analyses performed herein, the design resistance equations for flexural buckling resistance set out in Clause 5.4.2 of EN 1993-1-4, as given by Eq. (24), where $\mathrm{f}_{\mathrm{y}}$ is the material yield (0.2\% proof) strength, $\mathrm{A}$ is the cross-sectional area (taken as the gross cross-sectional area for Class 1, 2 and 3 sections and effective cross-sectional area $\mathrm{A}_{\text {eff }}$ for Class 4 sections), $\gamma_{\mathrm{M} 1}$ is the partial factor for member resistance and $\chi$ is the flexural buckling reduction factor, were expressed in a modified form, as presented in Eq. (25). The purpose of this was to separate the dependency of the buckling reduction factor $\chi$ on the basic variables (A and $\mathrm{f}_{\mathrm{y}}$ ) in the design model. In Eq. (25), $\mathrm{k}$ is a model constant, independent of $A$ and $f_{y}$, and $a$ and $b$ are the model parameters specific to each test specimen and vary with column slenderness; their values have been evaluated following the procedures set out in [10].

$$
\begin{gathered}
\mathrm{N}_{\mathrm{b}, \mathrm{Rd}}=\frac{\chi \mathrm{Af}_{\mathrm{y}}}{\gamma_{\mathrm{M} 1}} \quad \text { for } \quad \bar{\lambda} \geq \bar{\lambda}_{0} \\
\mathrm{~N}_{\mathrm{b}, \mathrm{Rd}}=\mathrm{kf}_{\mathrm{y}}^{\mathrm{a}} \mathrm{A}^{\mathrm{b}}
\end{gathered}
$$

A summary of the key results of the reliability analysis is presented in Table 3 and Table 4 for the coldformed and hot-finished SHS/RHS columns, respectively, and Table 5 for hot-finished CHS columns, where $\mathrm{k}_{\mathrm{d}, \mathrm{n}}$ is the design (ultimate limit state) fractile factor for $\mathrm{n}$ tests, where $\mathrm{n}$ is the population of test and FE data under consideration; $b$ is the mean value correction factor; $\mathrm{V}_{\delta}$ is the coefficient of variation of the test and FE results relative to the resistance model; and $\mathrm{V}_{\mathrm{r}}$ is the combined coefficient of variation incorporating the resistance model, the numerical model and the basic variable uncertainties. Note that the $\mathrm{b}$ parameter has been taken as the average of the experimental and FE to model prediction ratios (Eq. (26)), which, unlike the least squares approach recommended in Annex D, does not bias the value of $b$ towards the test or FE results with higher failure loads. For cold-formed SHS/RHS columns, the reliability study conducted in [10] showed that the required partial safety factors for the existing EN 1993-1-4 buckling curves were 1.16, 1.22 and 1.24 for the austenitic, duplex and ferritic stainless steel grades, respectively; these are above the current recommended value of 1.1. However, with the new buckling curves proposed herein, a $\gamma_{\mathrm{M} 1}$ value of 1.1 is now suitable. This is also the case for the newly proposed buckling curves for the hot-finished SHS/RHS and CHS members.

$$
\mathrm{b}=\frac{1}{\mathrm{n}} \sum\left(\mathrm{r}_{\mathrm{e}} / \mathrm{r}_{\mathrm{t}}\right)
$$

\section{Conclusions}

A set of standardised representative values for key strength and ductility material parameters for use in numerical parametric investigations of stainless steel structures have been recommended in this paper. The values were derived based on the analysis of an extensive database of stainless steel material stressstrain curve results, collected in $[10,11]$. For each family of stainless steel grades - austenitic, duplex and ferritic - standardised material parameters for three product types that exhibit similar characteristics, (1) hot-rolled sections, hot-rolled plates and sheets and cold-formed sheets, (2) flat faces of cold-formed box-sections and curved walls of cold-formed CHS and (3) corner regions of cold- 
formed box-sections and corner regions of press-braked sections were recommended. Following this, a finite element (FE) modelling study, incorporating the standardised material parameters, was carried out. The FE generated structural performance data, combined with column test data from the literature, were employed to derive buckling curves for the design of stainless steel square, rectangular and circular hollow sections (SHS/RHS and CHS) compression members from two production routes - cold-formed and hot-finished, and three stainless steel families - austenitic, duplex and ferritic. The suitability of the proposed buckling curves was confirmed by means of reliability analyses.

\section{References}

[1] EN 1993-1-4, Eurocode 3: Design of Steel Structures - Part 1-4: General Rules - Supplementary Rules for Stainless Steels, European Committee for Standardization, Brussels, 2015.

[2] SEI/ASCE-8, Specification for the Design of Cold-formed Stainless Steel Structural Members, American Society of Civil Engineers, Reston, 2002.

[3] AS/NZS 4673, Cold-formed Stainless Steel Structures, Australian/New Zealand Standard, Sydney, 2001.

[4] AISC, Design Guide 27: Structural Stainless Steel, American Institute of Steel Construction, 2013.

[5] Stainless Steel Design Manual. fourth edition, Steel Construction Institute (SCI), 2017.

[6] E. Mirambell, E. Real, On the calculation of deflections in structural stainless steel beams: an experimental and numerical investigation, J. Constr. Steel Res. 54 (1) (2000) 109-133.

[7] K.J.R. Rasmussen, Full-range stress-strain curves for stainless steel alloys, J. Constr. Steel Res. 59 (1) (2003) $47-61$.

[8] L. Gardner,M. Ashraf, Structural design for non-linearmetallic materials, Eng. Struct. 28 (6) (2006) 926-934.

[9] S. Afshan, B. Rossi, L. Gardner, Strength enhancements in cold-formed sections - part I: material testing, J. Constr. Steel Res. 83 (2013) 177-188.

[10] S. Afshan, L. Gardner, P. Francis, N.R. Baddoo, Reliability analysis of structural stainless steel design provisions, J. Constr. Steel Res. 114 (2015) 239-304.

[11] I. Arrayago, E. Real, L. Gardner, Description of stress-strain curves for stainless steel alloys, Mater. Des. 87 (2015) 540-552.

[12] L. Gardner, D.A. Nethercot, Experiments on stainless steel hollow sections - part 1: material and crosssectional behaviour, J. Constr. Steel Res. 60 (9) (2004)

$1291-1318$.

[13] B. Rossi, S. Afshan, L. Gardner, Strength enhancements in cold-formed sections - part II: predictive models, J. Constr. Steel Res. 83 (2013) 189-196.

[14] M. Bock, L. Gardner, E. Real, Material and local buckling response of ferritic stainless steel sections, ThinWalled Struct. 89 (2015) 131-141.

[15] K.J.R. Rasmussen, J. Rondal, Column curves for stainless steel alloys, J. Constr. Steel Res. 54 (2000) 89107.

[16] ABAQUS Version 6.14-1., Dassault Systmes Simulia Corp. USA, 2014.

[17] O. Zhao, S. Afshan, L. Gardner, Structural response and continuous strength method design of slender stainless steel cross-sections, Eng. Struct. 140 (2017) 14-25.

[18] O. Zhao, L. Gardner, B. Young, Buckling of ferritic stainless steel members under combined axial compression and bending, J. Constr. Steel Res. 117 (2016) 35-48.

[19] J.K. Sonu, K.J. Singh, Shear characteristics of Lean Duplex Stainless Steel (LDSS) rectangular hollow beams, Structure 10 (2017) 13-29.

[20] H.T. Li, B. Young, Cold-formed ferritic stainless steel tubular structuralmembers subjected to concentrated bearing loads, Eng. Struct. 145 (2017) 392-405. 
[21] M. Kucukler, L. Gardner, L. Macorini, Lateral-torsional buckling assessment of steel beams through a stiffness reduction method, J. Constr. Steel Res. 109 (2015)87-100.

[22] C. Buchanan, E. Real, L. Gardner, Testing, simulation and design of cold-formed stainless steel CHS columns, Thin-Walled Struct. (2017) (submitted).

[23] R.B. Cruise, L. Gardner, Strength enhancements induced during cold forming of stainless steel sections, J. Constr. Steel Res. 64 (11) (2008) 1310-1316.

[24] L. Gardner, N. Saari, F. Wang, Comparative experimental study of hot-rolled and cold-formed rectangular hollow sections, Thin-Walled Struct. 48 (7) (2010)

495-507.

[25] EN 1993-1-1, Eurocode 3: Design of Steel Structures - Part 1-1: General Rules and Rules for Buildings, European Committee for Standardization, Brussels, 2005.

[26] L. Gardner, D.A. Nethercot, Numerical modelling of stainless steel structural components - a consistent approach, J. Struct. Eng. ASCE 130 (10) (2004) (1586-1061).

[27] O. Zhao, L. Gardner, B. Young, Structural performance of stainless steel circular hollow sections under combined axial load and bending - part 1: experiments and numerical modelling, Thin-Walled Struct. 101 (2016) 231-239.

[28] M. Theofanous, L. Gardner, Testing and numerical modelling of lean duplex stainless steel hollow section columns, Eng. Struct. 31 (12) (2009) 3047-3058.

[29] S. Afshan, L. Gardner, Experimental study of cold-formed ferritic stainless steel hollow sections, J. Struct. Eng. ASCE 139 (5) (2013) 717-728.

[30] B. Young, Y. Liu, Experimental investigation of cold-formed stainless steel columns, J. Struct. Eng. ASCE 129 (2) (2003) 169-176.

[31] Y. Liu, B. Young, Buckling of stainless steel square hollowsection compressionmembers, J. Constr. Steel Res. 59 (2) (2003) 165-177.

[32] B. Young, W.M. Lui, Tests of cold-formed high strength stainless steel compression members, Thin-Walled Struct. 44 (2) (2006) 224-234.

[33] B. Young, W. Hartono, Compression tests of stainless steel tubular members, J. Struct. Eng. ASCE 128 (6) (2002) 754-761.

[34] B.A. Burgan, N.R. Baddoo, K. Gilsenan, Structural design of stainless steel members - comparison between Eurocode 3, part 1.4 and test results, J. Constr. Steel Res. 54 (1) (2000) 51-73.

[35] L. Gardner, D.A. Nethercot, Experiments on stainless steel hollow sections part 2: member behaviour of columns and beams, J. Constr. Steel Res. 60 (9) (2004) 1319-1332.

[36] L. Gardner, A. Talja, N.R. Baddoo, Structural design of high-strength austenitic stainless steel, Thin-Walled Struct. 44 (5) (2006) 517-528.

[37] B. Young, W.M. Lui, Behaviour of cold-formed high strength stainless steel sections, J. Struct. Eng. ASCE 131 (11) (2005) 1738-1745.

[38] K.J.R. Rasmussen, D.A. Hancock, Design of cold-formed stainless steel tubular members. I: columns, J. Struct. Eng. ASCE 119 (8) (1993) 2349-2367.

[39] H. Kuwamura, Local buckling of thin-walled stainless steel members, Int. J. Steel Struct. 3 (3) (2003) 191201.

[40] Y. Huang, B. Young, Material properties of cold-formed lean duplex stainless steel sections, Thin-Walled Struct. 54 (2012) 72-81.

[41] N.R. Baddoo, L. Gardner, Final Report. ECSC Project Development of the Use of Stainless Steel in Construction. Technical Report RT810, Contract No. 7210 SA/842, The Steel Construction Institute, UK, 2000.

[42] SCI, Tests on Stainless Steel Materials. SCI-RT-251, The Steel Construction Institute, UK, 1991. 
[43] T. Ala-Outinen, Stainless Steel in Fire (SSIF).Work Package 3:MembersWith Class 4 Cross-sections in Fire. RFS-CR-04048, The Steel Construction Institute, UK, 2007.

[44] M. Theofanous, T.M. Chan, L. Gardner, Structural response of stainless steel oval hollow section compression members, Eng. Struct. 31 (4) (2009) 922-934.

[45] E. Ellobody, B. Young, Investigation of cold-formed stainless steel non-slender circular hollow section columns, Steel Compos. Struct. 7 (4) (2007) 321-337.

[46] M. Ashraf, L. Gardner, D.A. Nethercot, Resistance of stainless steel CHS columns based on cross-section deformation capacity, J. Constr. Steel Res. 64 (9) (2008) 962-970.

[47] EN 1990, Eurocode: Basis of Structural Design, European Committee for Standardization, Brussels, 2002.

[48] M. Bock, F.X. Mirada, E. Real, Statistical evaluation of a new resistance model for cold-formed stainless steel cross-sections subjected to web crippling, Int. J. Steel Struct. 15 (1) (2015) 227-244.

[49] R.B. Cruise, L. Gardner, Measurement and prediction of geometric imperfections in structural stainless steel members, Struct. Eng. Mech. 24 (1) (2006) 63-89.

[50] H.X. Yuan, Y.Q. Wang, L. Gardner, Y.J. Shi, Local-overall interactive buckling of welded stainless steel box section compression members, Eng. Struct. 67 (2014) 62-76.

[51] H.X. Yuan, Y.Q.Wang, L. Gardner, X.X. Du, Y.J. Shi, Local-overall interactive buckling behaviour of welded stainless steel I-section columns, J. Constr. Steel Res. 111 (2015) 75-87.

[52] L. Gardner, R.B. Cruise,Modelling of residual stresses in structural stainless steel sections, J. Struct. Eng. ASCE 135 (1) (2009) 42-53.

[53] H.X. Yuan, Y.Q. Wang, Y.J. Shi, L. Gardner, Residual stress distributions in welded stainless steel sections, Thin-Walled Struct. 79 (2014) 38-51.

[54] M. Jandera, J. Machacek, Residual stress influence on material properties and column behaviour of stainless steel SHS, Thin-Walled Struct. 83 (2014) 12-18. 


\section{Tables}

Table 1: Representative Ramberg-Osgood material model parameters for numerical parametric studies.

\begin{tabular}{|c|c|c|c|c|c|c|c|c|c|c|c|c|}
\hline \multirow{2}{*}{ Material type } & \multirow{2}{*}{ Structural sections } & \multirow{2}{*}{ Grade } & \multicolumn{5}{|c|}{ Basic material properties } & \multicolumn{3}{|c|}{ Section specific material properties* } & \multirow{2}{*}{$\begin{array}{c}\text { Geometric } \\
\text { imperfections }\end{array}$} & \multirow{2}{*}{$\begin{array}{c}\text { Residual stress } \\
\text { model }\end{array}$} \\
\hline & & & $f_{y}$ & $\mathrm{f}_{\mathrm{u}}$ & $\varepsilon_{\mathrm{u}}$ & $\mathrm{n}$ & $\mathrm{m}$ & $f_{y, c f}$ & $\mathrm{f}_{\mathrm{u}, \mathrm{cf}}$ & $\varepsilon_{\mathrm{u}, \mathrm{cf}}$ & & \\
\hline \multirow{3}{*}{$\begin{array}{l}\text { Hot-rolled } \\
\text { sections }\end{array}$} & & $\bar{A}$ & 280 & 580 & 0.50 & 9.1 & 2.3 & \multirow{3}{*}{-} & \multirow{3}{*}{-} & \multirow{3}{*}{-} & \multirow{3}{*}[25,26,49]{} & \multirow{3}{*}[52,53]{} \\
\hline & & $\mathrm{D}$ & 530 & 770 & 0.30 & 9.3 & 3.6 & & & & & \\
\hline & & $\mathrm{F}$ & 320 & 480 & 0.16 & 17.2 & 2.8 & & & & & \\
\hline \multirow{3}{*}{$\begin{array}{l}\text { Hot-rolled } \\
\text { plate/sheet (to } \\
\text { form welded } \\
\text { profiles) }\end{array}$} & & $\mathrm{A}$ & 280 & 580 & 0.50 & 9.1 & 2.3 & \multirow{3}{*}{-} & \multirow{3}{*}{-} & \multirow{3}{*}{-} & \multirow{3}{*}[50,51]{} & \multirow{3}{*}[52,53]{} \\
\hline & & $\mathrm{D}$ & 530 & 770 & 0.30 & 9.3 & 3.6 & & & & & \\
\hline & & $\mathrm{F}$ & 320 & 480 & 0.16 & 17.2 & 2.8 & & & & & \\
\hline \multirow{3}{*}{$\begin{array}{l}\text { Cold-rolled } \\
\text { sheet/flat regions } \\
\text { of press-braked } \\
\text { sections }\end{array}$} & & $\bar{A}$ & 280 & 580 & 0.50 & 9.1 & 2.3 & \multirow{3}{*}{-} & \multirow{3}{*}{-} & \multirow{3}{*}{-} & \multirow{3}{*}{ [49] } & \multirow{3}{*}[52,54]{} \\
\hline & & D & 530 & 770 & 0.30 & 9.3 & 3.6 & & & & & \\
\hline & & F & 320 & 480 & 0.16 & 17.2 & 2.8 & & & & & \\
\hline \multirow{3}{*}{$\begin{array}{l}\text { Corner regions of } \\
\text { press-braked } \\
\text { sections }\end{array}$} & & $\bar{A}$ & 640 & 830 & 0.20 & 6.4 & 7.1 & \multirow{3}{*}{ Eq. (3) } & & & \multirow{3}{*}{ [49] } & \multirow{3}{*}[52,54]{} \\
\hline & & D & 800 & 980 & 0.03 & 6.1 & 6.7 & & & & & \\
\hline & & F & 560 & 610 & 0.01 & 5.7 & 6.8 & & & & & \\
\hline \multirow{3}{*}{$\begin{array}{l}\text { Flat faces of } \\
\text { cold-formed box- } \\
\text { sections/curved } \\
\text { walls of cold- } \\
\text { formed CHS }\end{array}$} & & $\bar{A}$ & 460 & 700 & 0.20 & 7.1 & 2.9 & \multirow{3}{*}{$\begin{array}{l}\text { Eq. (4) } \\
\text { Eq. (5) }\end{array}$} & & & \multirow{3}{*}[26,27]{} & \multirow{3}{*}[52,54]{} \\
\hline & & D & 630 & 780 & 0.13 & 7.5 & 4.8 & & Eq. (11) & Eq. (13) & & \\
\hline & & F & 430 & 490 & 0.06 & 11.5 & 4.6 & & Eq. (12) & Eq. (14) & & \\
\hline
\end{tabular}

Table 1: Summary of the proposed buckling curves

\begin{tabular}{lcccccccc}
\hline & \multicolumn{3}{c}{ SHS/RHS } & \multicolumn{5}{c}{ CHS } \\
\hline Grade & \multicolumn{1}{c}{ Cold-formed } & \multicolumn{2}{c}{ Hot-finished } & \multicolumn{2}{c}{ Cold-formed } & \multicolumn{3}{c}{ Hot-finished } \\
\hline Austenitic & $\alpha$ & $\bar{\lambda}_{0}$ & $\alpha$ & $\bar{\lambda}_{0}$ & $\alpha$ & $\bar{\lambda}_{0}$ & $\alpha$ & $\bar{\lambda}_{0}$ \\
Duplex & 0.49 & 0.3 & 0.49 & 0.2 & 0.49 & 0.2 & 0.49 & 0.2 \\
Ferritic & 0.49 & 0.3 & 0.49 & 0.2 & 0.49 & 0.2 & 0.49 & 0.2 \\
& 0.49 & 0.2 & 0.34 & 0.2 & 0.49 & 0.2 & 0.34 & 0.2 \\
\hline
\end{tabular}

Table 2: Summary of the reliability analysis results for cold-formed SHS/RHS stainless steel columns

\begin{tabular}{lcccccccc}
\hline Grade & $\mathrm{n}$ & $\mathrm{b}$ & $\begin{array}{c}\text { Over- } \\
\text { strength }\end{array}$ & $\mathrm{k}_{\mathrm{d}, \mathrm{n}}$ & $\mathrm{V}_{\delta}$ & $\mathrm{V}_{\text {fy }}$ & $\mathrm{V}_{\text {geometry }}$ & $\gamma_{\mathrm{M} 1}$ \\
\hline Austenitic & 285 & 1.075 & 1.3 & 3.12 & 0.071 & 0.060 & 0.05 & 1.08 \\
Duplex & 192 & 1.117 & 1.1 & 3.14 & 0.045 & 0.030 & 0.05 & 1.08 \\
Ferritic & 184 & 1.107 & 1.2 & 3.14 & 0.060 & 0.045 & 0.05 & 1.06 \\
\hline
\end{tabular}

Table 3: Summary of the reliability analysis results for hot-finished SHS/RHS stainless steel columns

\begin{tabular}{lcccccccc}
\hline Grade & $\mathrm{n}$ & $\mathrm{b}$ & $\begin{array}{c}\text { Over- } \\
\text { strength }\end{array}$ & $\mathrm{k}_{\mathrm{d}, \mathrm{n}}$ & $\mathrm{V}_{\delta}$ & $\mathrm{V}_{\text {fy }}$ & $\mathrm{V}_{\text {geometry }}$ & $\gamma_{\mathrm{M} 1}$ \\
\hline Austenitic & 160 & 1.050 & 1.3 & 3.15 & 0.056 & 0.060 & 0.05 & 1.05 \\
Duplex & 165 & 1.136 & 1.1 & 3.15 & 0.047 & 0.030 & 0.05 & 1.08 \\
Ferritic & 150 & 1.041 & 1.2 & 3.16 & 0.054 & 0.045 & 0.05 & 1.12 \\
\hline
\end{tabular}


Table 4: Summary of the reliability analysis results for hot-finished CHS stainless steel columns

\begin{tabular}{lcccccccc}
\hline Grade & $\mathrm{n}$ & $\mathrm{b}$ & $\begin{array}{c}\text { Over- } \\
\text { strength }\end{array}$ & $\mathrm{k}_{\mathrm{d}, \mathrm{n}}$ & $\mathrm{V}_{\delta}$ & $\mathrm{V}_{\text {fy }}$ & $\mathrm{V}_{\text {geometry }}$ & $\gamma_{\mathrm{M} 1}$ \\
\hline Austenitic & 53 & 1.066 & 1.3 & 3.29 & 0.057 & 0.060 & 0.05 & 1.06 \\
Duplex & 47 & 1.147 & 1.1 & 3.31 & 0.041 & 0.030 & 0.05 & 1.07 \\
Ferritic & 57 & 1.068 & 1.2 & 3.27 & 0.049 & 0.045 & 0.05 & 1.09 \\
\hline
\end{tabular}




\section{Figures}

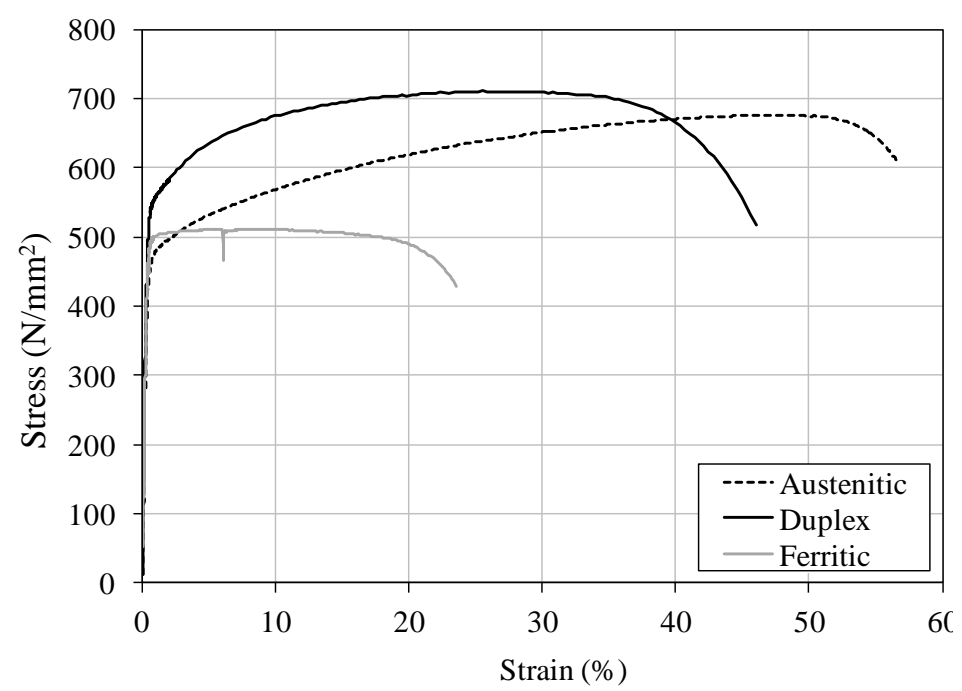

Fig. 1: Typical stress-strain curves for austenitic, duplex and ferritic stainless steels

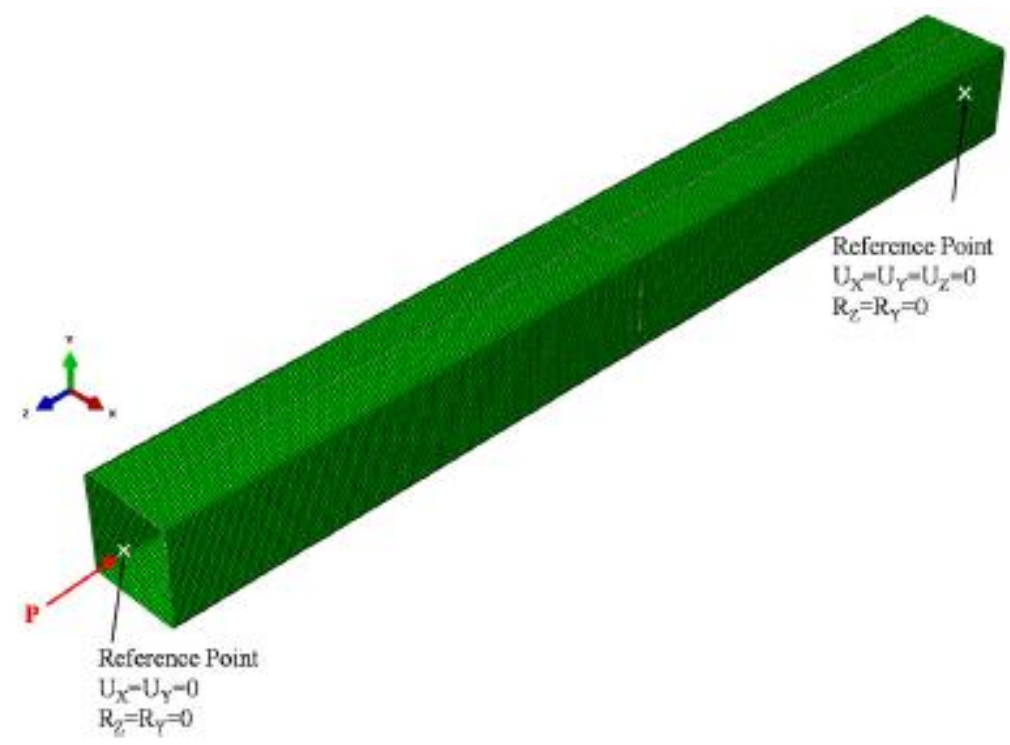

Fig. 2: Boundary conditions in the pin-ended column FE models. 


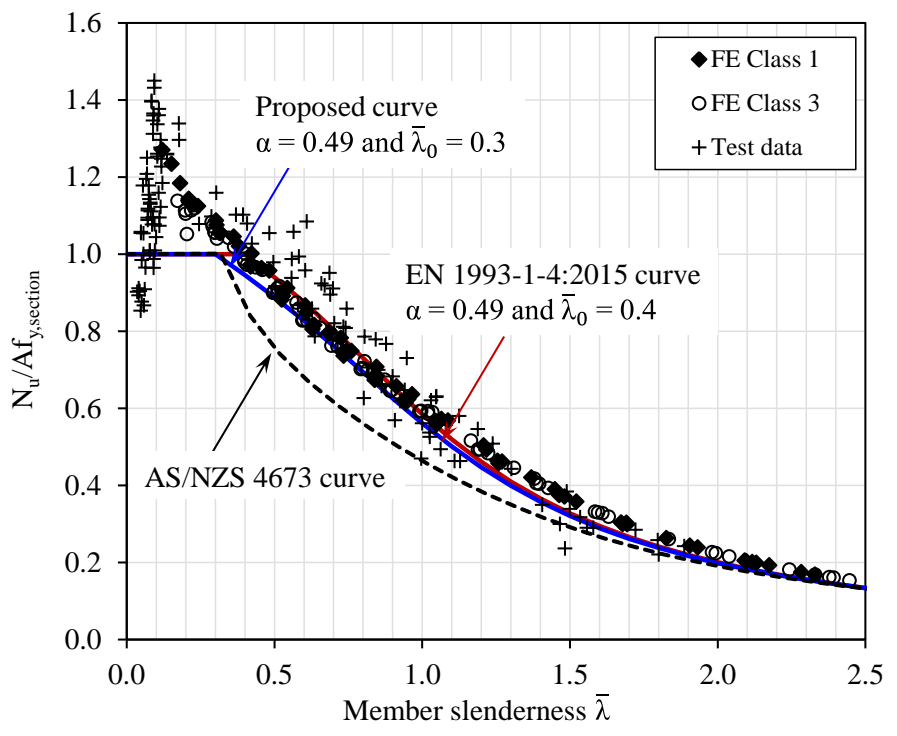

(a) Austenitic

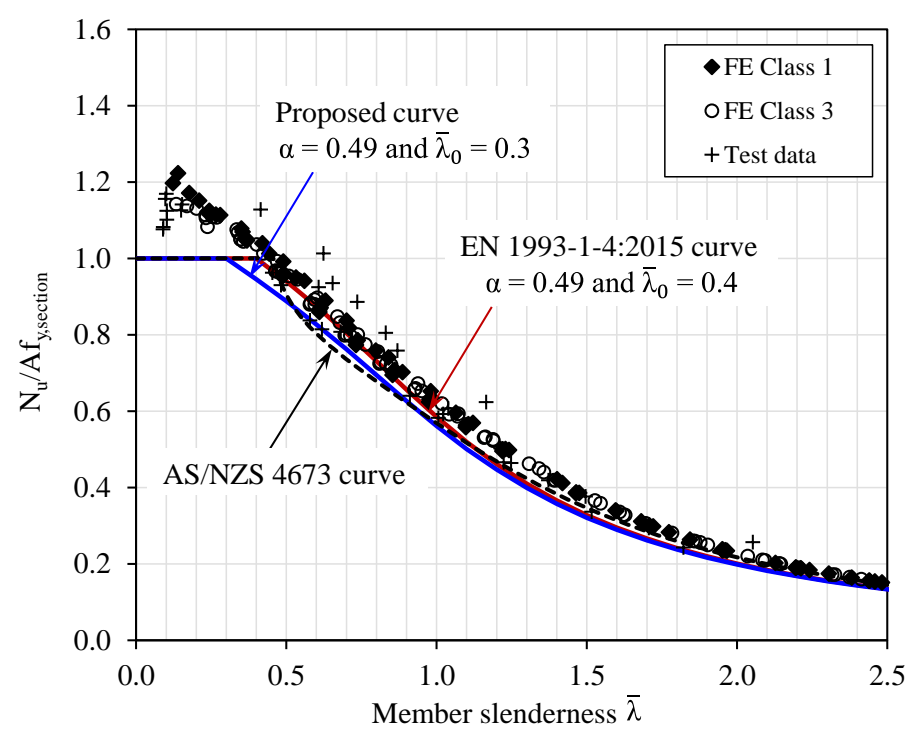

(b) Duplex

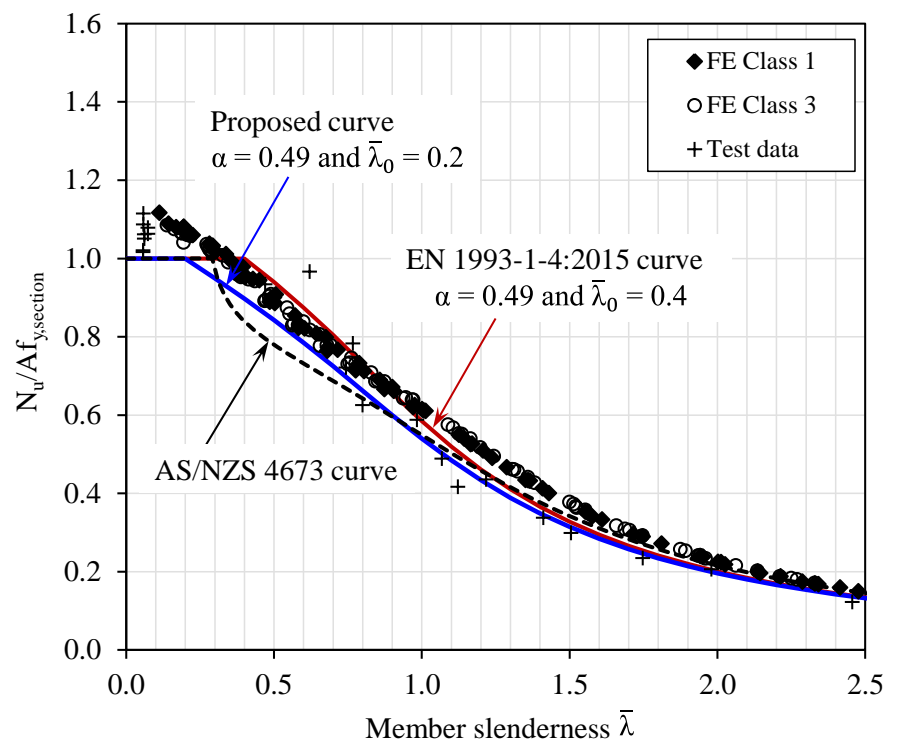

(c) Ferritic

Fig. 3: Buckling response of cold-formed (a) austenitic, (b) duplex and (c) ferritic SHS/RHS 


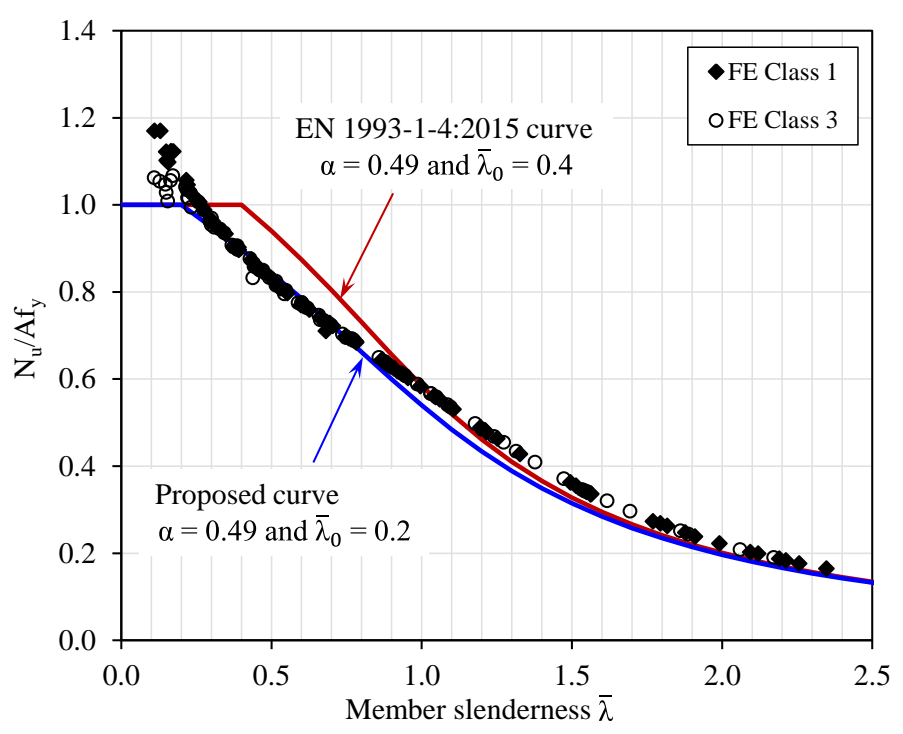

(a) Austenitic

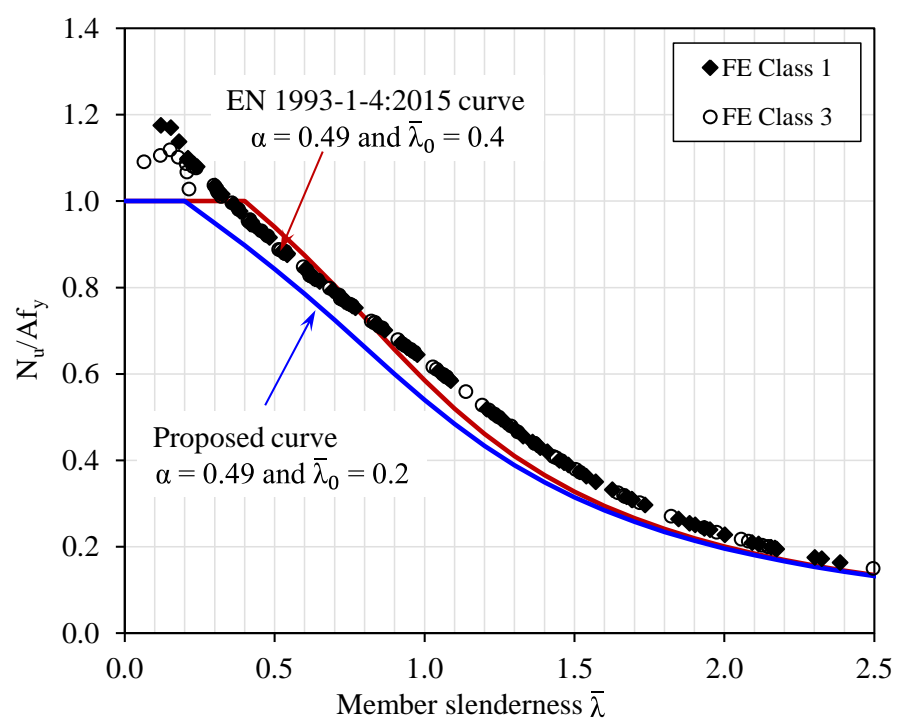

(b) Duplex

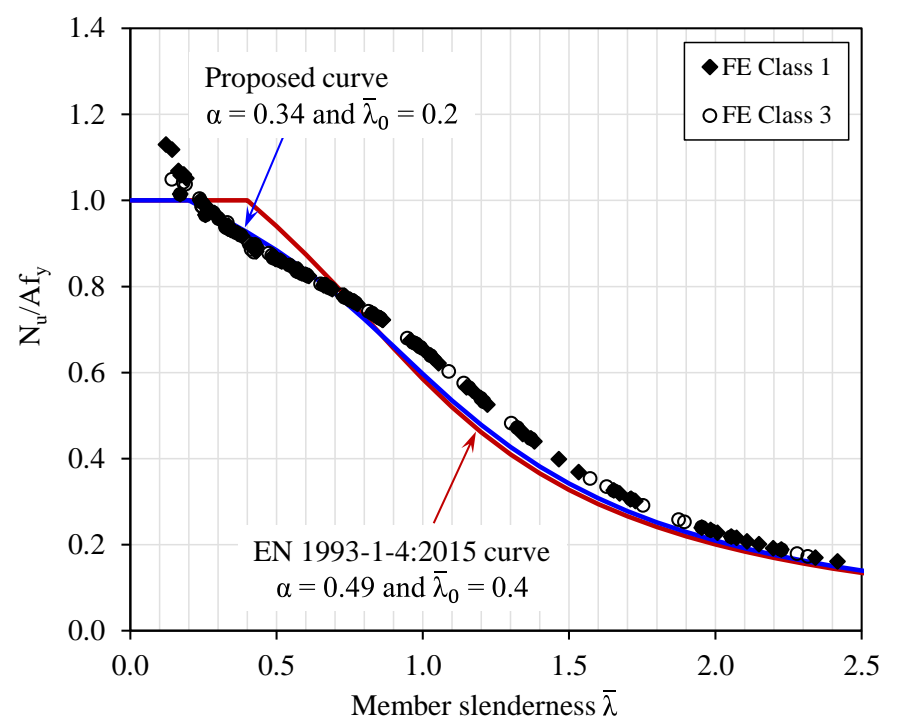

(c) Ferritic

Fig. 4: Buckling response of hot-finished (a) austenitic, (b) duplex and (c) ferritic SHS/RHS 


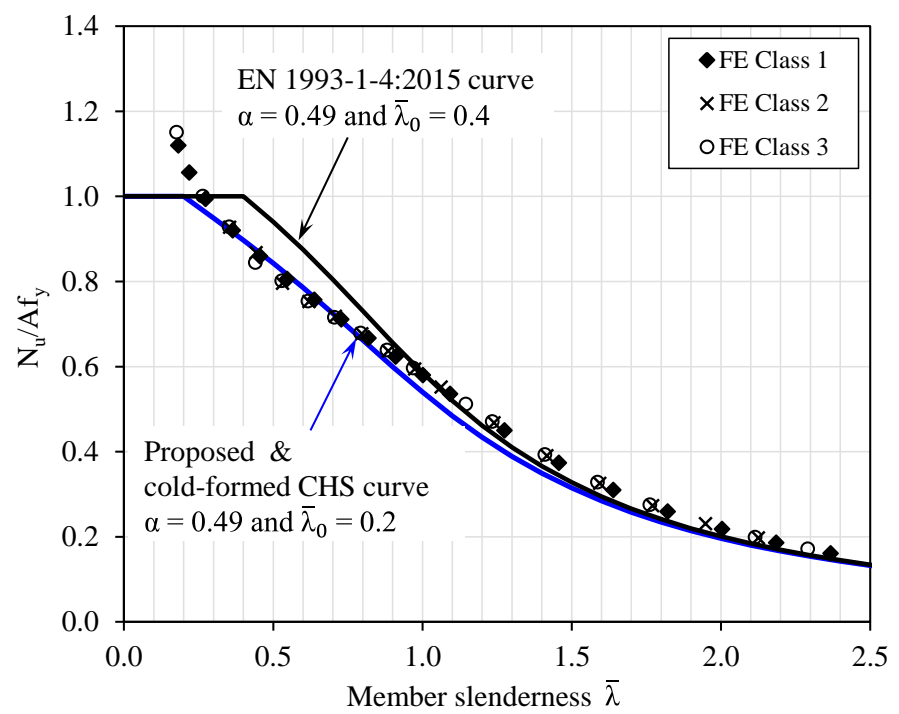

(a) Austenitic

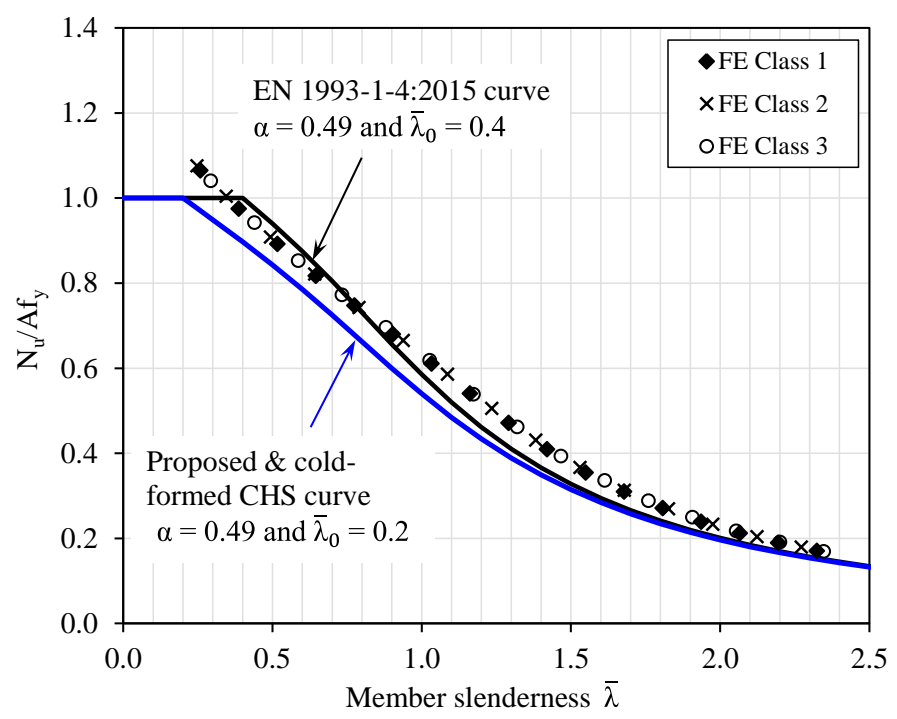

(b) Duplex

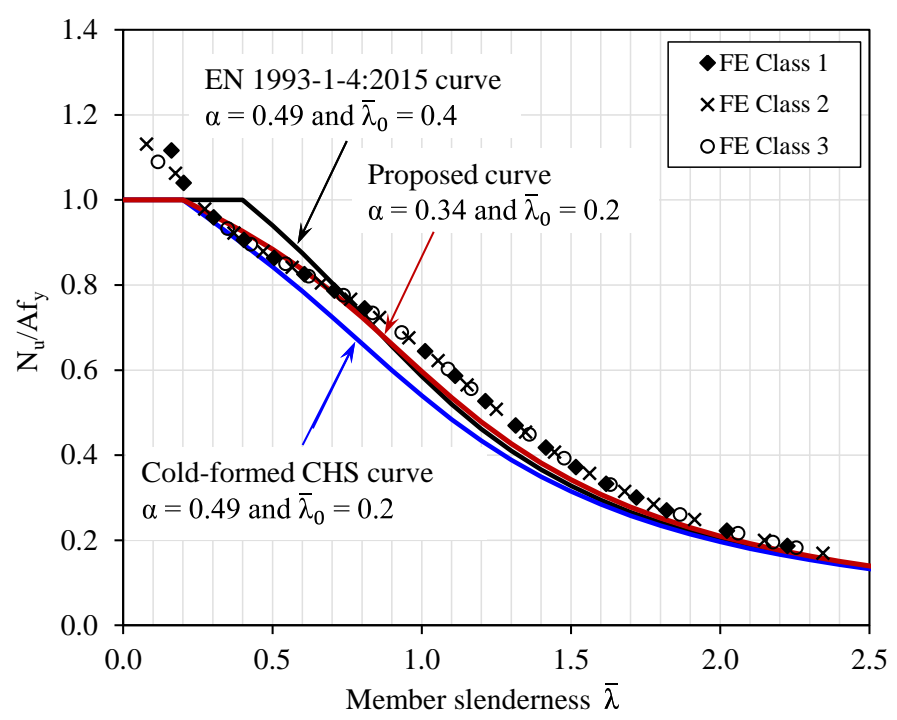

(c) Ferritic

Fig. 5: Buckling response of hot-finished (a) austenitic, (b) duplex and (c) ferritic CHS 